\title{
CÓMO HACER COSAS MALAS CON PALABRAS: ACTOS ILOCUCIONARIOS HOSTILES Y LOS FUNDAMENTOS DE LA TEORÍA DE LOS ACTOS DE HABLA
}

\author{
Antonio Blanco Salgueiro \\ Departamento de Lógica y Filosofía de la Ciencia \\ Facultad de Filosofía \\ Universidad Complutense de Madrid \\ ablancos@filos.ucm.es
}

RESUMEN: En el presente artículo se defiende que el estudio de una familia particular de actos de habla, los actos ilocucionarios hostiles, nos da la clave para reexaminar cuatro importantes cuestiones fundacionales de la teoría de los actos de habla: la distinción ilocucionario/perlocucionario, la noción de infortunio, la cuestión de la primacía de la primera sobre la tercera persona en el estudio de la fuerza, y la cuestión de la posibilidad de una teoría general y sistemática del fenómeno de la fuerza.

PALABRAS CLAVE: fuerza ilocucionaria, ilocucionario/perlocucionario, infortunio, primera persona/tercera persona

SUMMARY: In this paper I argue that the study of a particular family of speech acts, the hostile illocutionary acts, gives us the key for the re-examination of four important foundational questions in speech act theory: the illocutionary/perlocutionary distinction, the notion of infelicity, the question of the primacy of first versus third person perspective in the study of force, and the question of the possibility of a general and systematic theory of the phenomenon of force.

KEY WORDS: illocutionary force, illocutionary/perlocutionary, infelicity, first/third person

\section{El dominio de la investigación: hacer cosas malas con palabras}

Esta investigación quiere contribuir a resolver difíciles cuestiones fundacionales de la teoría de los actos de habla, la principal de las cuales es la siguiente: ¿Qué es una fuerza ilocucionaria? A pesar de la abundante literatura en el área, no disponemos de una caracterización satisfactoria de la fuerza, ni hemos avanzado mucho desde la vaga observación de J.L. Austin de que la fuerza consiste en cómo deben ser tomadas las palabras, o el todavía más vago criterio lingüístico de que un acto ilocucionario es el que realizamos al decir lo que decimos, y no el de decir lo que decimos (locucionario), o el que realizamos por decir lo que decimos (perlocucionario). En otros 
lugares hemos intentado una aproximación directa a esta cuestión. ${ }^{1}$ Aquí se emprende un camino indirecto. Se parte del estudio de una familia particular de actos de habla, la de los actos de habla hostiles y/o socialmente mal vistos (en adelante, AHH/SMV), con el propósito de plantear cuestiones fundacionales generales. Un objetivo más específico consiste en arrojar luz sobre una región poco explorada del uso del lenguaje, la de la hostilidad verbal. El dominio puede ser caracterizado de modo preliminar mediante la siguiente lista de verbos (y nombres) del castellano:

abroncar, abuchear, acriminar, acusar, afrentar, agraviar, alardear, amenazar, amonestar, anular, baladronada, befar(se), blasfemar, burlar(se), calumniar, censurar, cesar, cháchara, chantajear, charlatanería, chismear, chismorrear, chivar(se), chocarrear, chulear(se), sembrar cizaña, condenar, contradecir, corregir, cotillear, criminalizar, criminar, criticar, cuchichear, culpar, dar falso testimonio, dar el soplo, dar un ultimátum, declarar (la guerra, culpable), degradar, delatar, hacer demagogia, demandar, demonizar, denegar, denigrar, denostar, denunciar, desacatar, desafiar, desaprobar, descalificar, desheredar, desmentir, despedir, destituir, diatriba, dicterio, difamar, discrepar, disentir, echar en cara, echar leña al fuego, echar un rapapolvo, escarnecer, soltar un exabrupto, exagerar, excomulgar, extorsionar, execrar, expulsar, fanfarronear, fantasmada, fardar, farolear, hacer guasa, imprecar, improperar, impugnar, imputar, increpar, incriminar, infamar, infundio, injuriar, insultar, interrumpir, intoxicar, invalidar, invectiva, jactar(se), lanzar puyas, libelo, maldecir, maledicencia, mandar a hacer puñetas (a freir espárragos, a la mierda, al carajo...), mofar(se), multar, murmurar, objetar, oponer(se), oprobiar, decir paparruchas, patraña, poner a caer de un burro, poner a caldo, poner reparos, presionar, presumir, prevaricar, proscribir, protestar, rebajar (de categoría), rebatir, rechazar, rechistar, rechiflar, reclamar, reconvenir, recriminar, recusar, refunfuñar, regañar, refutar, rehusar, reñir, replicar, reprender, reprobar,

\footnotetext{
${ }^{1}$ El enfoque general en el que se enmarca este trabajo se presenta en Blanco Salgueiro 2004a, 2004b y 2007. En esas obras se defiende, contra lo que se considera la postura ortodoxa, que entre las condiciones constitutivas de una fuerza ilocucionaria típica hay que dar protagonismo a factores no analizables en términos de intenciones u otros estados mentales del emisor (ni siquiera si añadimos el reconocimiento de los mismos por parte de la audiencia). Denominamos a ese marco general "externismo ilocucionario" (frente a posturas "internistas" o "mentalistas" acerca de la fuerza).
} 
repudiar, repulsar, retar, rezongar, ridiculizar, sancionar, satanizar, sentenciar, silbar, soltar palabrotas, soltar picadas, soltar tacos, suspender, tachar (de), tergiversar, tildar (de), ultrajar, vanagloriarse, vetar, vilipendiar, vituperar, vociferar.

La lista es un tanto heterogénea, pero existe un claro "parecido de familia" que unifica el conjunto. Dejando de lado un par de casos (abuchear, silbar), se trata de verbos de actos de habla, que apuntan, como sedimentación léxica de ciertas prácticas, a cosas que hacemos con palabras. Ahora bien, ¿qué los distingue de otros tipos de actos de habla como afirmar, pedir, prometer o advertir? La característica más importante, utilizada inicialmente como criterio para elaborar la lista, es la de hostilidad (verbal). La mayoría de los verbos apuntan a actos intrínsecamente hostiles, que ocurren típicamente en situaciones de conflicto interpersonal (verbalmente mediado): enfrentamientos, desencuentros, discusiones, luchas de poder, etc. Se trata de actos inherentemente descorteses. Algunos son tales que es posible mitigar en parte su potencial hostil mediante ciertos mecanismos de cortesía, o gracias a que se insertan en contextos ritualizados (congresos y conferencias, por ejemplo). Así: "Espero que no se moleste si le hago la siguiente objeción..." Por supuesto, en el contexto apropiado, prácticamente cualquier tipo de acto de habla puede tener un uso hostil. Una simple pregunta, una afirmación aparentemente inocente, pueden resultar terribles, ofensivas o letales. Pero eso ocurrirá en el plano de las consecuencias (en un plano perlocucionario), y se deberá al contenido, no al tipo de acto realizado; aquí nos interesan los tipos de actos de habla inherentemente hostiles o que, al menos, contienen inherentemente un potencial (mayor o menor) de hostilidad. Precisamente por su hostilidad, por poner en riesgo la armonía de las relaciones sociales, típicamente los actos de habla hostiles están socialmente (o moralmente) mal vistos, y son considerados con reprobación. Es más, algunos de esos actos verbales son ilegales, ya que realizarlos (o perpetrarlos) con éxito es cometer delitos (o faltas) con palabras (es el caso de injurias, calumnias, amenazas, extorsiones, prevaricaciones o falsos testimonios). Dada la importancia de este rasgo de lo socialmente inaceptable, se han incluido algunos verbos que no apuntan tanto a la hostilidad como al carácter reprobable del acto (así, jactarse o cuchichear). Sin embargo, este rasgo de lo socialmente mal visto tampoco es absoluto. Para empezar, muchos de esos actos pueden verse como justificados o legítimos en ocasiones ¿No estoy justificado a denunciar a 
alguien, si me ha robado; o a criticarlo si ha hecho algo malvado; o incluso a insultarlo, si me ha ofendido gravemente? Además, la hostilidad puede ser un modo de control social institucionalizado y, de ese modo, estar socialmente legitimada (caso de multas, prohibiciones, degradaciones, demandas, sentencias, condenas, etcétera).

Utilizaremos la noción de hostilidad (y la de "rebrobabilidad") de un modo más bien intuitivo, aunque nuestros argumentos centrales son compatibles con diversas definiciones técnicas de esa noción clave. Una noción mejor perfilada y útil para las investigaciones pragmáticas podría obtenerse a partir la amplia literatura sobre el fenómeno de la cortesía verbal, ${ }^{2}$ y debería estar sustentada por una teoría sociológica acerca de la interacción social. De hecho, podemos definir la hostilidad (verbal) negativamente, como aquello que es incompatible con la cortesía, como el reverso (extremo) de la cortesía, o como una forma especialmente no mitigable de descortesía. ${ }^{3}$

Contamos, pues, con un dominio bastante unitario de tipos de acciones que consisten en hacer cosas malas con palabras. Hemos dejado fuera algunos candidatos para no aumentar la heterogeneidad de nuestro objeto de estudio. Tal vez deberían aparecer mentir e insinuar; y chorrada, chuminada, tontería o bobada; y disparate o despropósito; y verbos de actos de habla impositivos, como exigir, mandar, ordenar o urgir, que pueden resultar hostiles a menos que se utilicen mecanismos de cortesía. Y tal vez algunos de los verbos incluidos no merecerían estar en la lista. Es difícil decidir con detalle qué debe ser incluido, a menos que carguemos de entrada con un marco teórico determinado. Lo importante es que contamos con un punto de partida rico y preteóricamente bastante sólido, a partir del cual plantear cuestiones acerca de los fundamentos de la teoría de los actos de habla. En la elaboración del listado de la "infamia" ver-

${ }^{2}$ Cfr. Lakoff 1973, Leech 1983, Brown y Levinson 1978/1987, Eelen 2001, Watts 2003, Watts et al. 1992/2005.

${ }^{3} \mathrm{El}$ problema es que existe una gran variedad de enfoques acerca del fenómeno de la cortesía verbal. El más influyente es el de Brown y Levinson (1978/1987), según el cual los mecanismos de la cortesía tienen como función la preservación de la imagen pública (face) de los interlocutores. En todos los ejemplos de nuestra lista parece darse que quienes realizan con éxito el acto en cuestión hacen peligrar la imagen pública de alguien, en general la de la audiencia, aunque en otros casos (en las jactancias, por ejemplo) la que sufre es la imagen pública del propio hablante. Un problema del enfoque de Brown y Levinson, y de la mayoría de las teorías "clásicas" de la cortesía, es que prestan atención, sobre todo, a los modos de preservar la cortesía, y apenas prestan atención positiva a su reverso. 
bal hemos seguido el segundo de los métodos de filosofía lingüística propuestos por Austin en "A Plea for Excuses":

Primero podemos usar el diccionario - uno muy conciso valdrá, pero el uso debe ser amplio - . Dos métodos parecen sugerirse, ambos un poco tediosos, pero que compensan. Uno consiste en leer el libro de arriba abajo, anotando todas las palabras que parecen relevantes; esto no lleva tanto tiempo como pudiera suponerse. El otro consiste en partir de una más bien extensa selección de términos obviamente relevantes y consultar en el diccionario cada uno; se encontrará que, en las explicaciones de los diversos significados de cada uno, figura un sorprendente número de términos distintos que son pertinentes, aunque, por cierto, no frecuentemente sinónimos. Luego miramos cada uno de éstos, echando más en nuestra bolsa a partir de las 'definiciones' dadas en cada caso; y cuando hemos continuado haciéndolo durante un rato, se encontrará generalmente que el círculo familiar empieza a cerrarse, hasta que finalmente queda completo y nos topamos sólo con repeticiones. Este método tiene la ventaja de agrupar los términos en racimos apropiados - pero naturalmente mucho dependerá de la exhaustividad de nuestra selección inicial-. (Austin 1956/1957, p. 178)

La tarea interesante comienza una vez que tenemos la lista, cuando pasamos de la "primera palabra", otorgada al lenguaje ordinario, a la respuesta que debería proporcionar una teoría o enfoque explicativo acerca de la hostilidad verbal.

\section{Un fenómeno nada excepcional}

Lo primero que pone de relieve la lista es la amplitud del territorio de los AHH/SMV, si juzgamos a partir de la sedimentación léxica. Estamos ante una vasta región dentro del territorio de las cosas que hacemos con palabras, que ninguna teoría general de los actos de habla puede dejar fuera de su consideración. La amplitud es tanto cualitativa (la lista apunta a unos 150 tipos de actos de habla diferentes), ${ }^{4}$ como cuantitativa (piénsese en las emisiones de los políticos en la crispada arena política española, y hágase un cálculo aproximado de cuántas de ellas ejemplifican alguno de los tipos de la lista). De

\footnotetext{
${ }^{4}$ La sedimentación léxica es sólo un índice fiable de la variedad de cosas que hacemos con palabras. Lo importante teóricamente son los tipos de actos de habla, no los verbos ordinarios asociados a ellos ( $c f r$. Searle 1975). En particular, algunos de los miembros de la lista podrían ser (cuasi)sinónimos y, por otra parte, podríamos no contar con verbos para todas las cosas hostiles que podemos hacer con palabras.
} 
hecho, hay una gran riqueza en la lista, y tal vez sea posible establecer en su interior una taxonomía basada en ciertos criterios o principios. ${ }^{5}$

Sin embargo, en la literatura se tiende a tratar a esos actos verbales como marginales o excepcionales, incluso como aberrantes. Se presupone que los AHH/SMV constituyen un territorio pequeño y periférico, que no merece mucho la pena explorar, y que no debe marcar la pauta de una teoría general de los actos de habla. De hecho, casi siempre se citan los mismos ejemplos: amenazas, insultos y poco más. La realidad es que el territorio es enormemente rico y diverso, y que la apariencia de marginalidad se debe a un conjunto de arraigados prejuicios teóricos. Si juzgamos por la cantidad de verbos y nombres de actos de habla hostiles que encontramos en el léxico de las distintas lenguas, debemos concluir que el fenómeno dista de ser excepcional. El método de Austin hace aflorar gran cantidad de material conceptual ordinario que, de otra manera, sería difícil de identificar, debido a tales prejuicios. Los principales sesgos

${ }^{5}$ Wierzbicka (1987) establece 37 grupos de verbos ilocucionarios, varios de los cuales representan familias de AHH/SMV. Tanto la clasificación de Austin (1962) (en judicativos, ejercitativos, compromisivos, comportativos y expositivos) como la de Searle (1975) (en representativos, directivos, compromisivos, expresivos y declarativos) reparten los $\mathrm{AHH} / \mathrm{SMV}$ entre las diversas categorías. El siguiente agrupamiento aproximado está basado en el mencionado método de Austin:

ACUSAR: acriminar, calumniar, censurar, chivarse, criminalizar, criticar, criminar, culpar, dar el soplo, delatar, demandar, demonizar, denunciar, descalificar, difamar, echar en cara, imputar, incriminar, infamar, injuriar, tachar de, tildar de, satanizar, vituperar.

AMENAZAR: chantajear, dar un ultimátum, extorsionar.

ANULAR: cesar, condenar, denegar, excomulgar, expulsar, declarar culpable, degradar, desheredar, despedir, destituir, invalidar, multar, prohibir, proscribir, rebajar, repudiar, sancionar, sentenciar, suspender, vetar.

BLASFEMAR: exabrupto, palabrota, taco.

BURLARSE: befarse, chocarrear, guasearse, mofarse, rechiflar, ridiculizar.

CONTRADECIR: corregir, desaprobar, desmentir, discrepar, disentir, interrumpir, impugnar, objetar, oponerse, rebatir, rechazar, rechistar, refunfuñar, refutar, rehusar, replicar, rezongar.

COTILLEAR: chismear, chismorrear, cuchichear, maledicencia, murmurar.

DESAFIAR: declarar la guerra, desacatar, lanzar puyas, protestar, reclamar, recusar, retar.

INSULTAR: agraviar, afrentar, denigrar, denostar, diatriba, dicterio, escarnecer, execrar, improperar, imprecar, invectiva, maldecir, mandar a hacer puñetas (a freir espárragos, a la mierda, al carajo), oprobiar, poner a caer de un burro, poner a caldo, ultrajar, vilipendiar.

JACTARSE: alardear, chulearse, fanfarronear, fardar, presumir, vanagloriarse. REÑIR: abroncar, abuchear, amonestar, echar un rapapolvo, increpar, reconvenir, recriminar, regañar, reprender, reprobar, reprochar, repulsar, silbar.

TERGIVERSAR: exagerar, intoxicar, dar falso testimonio. 
que "ciegan" al teórico de los actos de habla ante este numeroso grupo de actos verbales parecen ser los siguientes:

1) Un énfasis excesivo en la cortesía y en la cooperatividad en la pragmática contemporánea, y una corrrespondiente falta de atención a sus contrarios. $^{6}$ Este énfasis es llevado al extremo cuando se presupone (como hace Habermas) que hay una ética incrustada en la actividad de conversar, marcada por una racionalidad comunicativa, buscadora del consenso, y no por una racionalidad estratégica o instrumental, orientada por la búsqueda de medios para conseguir fines egoístas. Bajo ese supuesto, los AHH/SMV aparecen como formas aberrantes de conversar, o incluso como formas de no conversar plenamente, con todas las de la ley.

2) Un énfasis excesivo en los estados mentales individuales del emisor. En los AHH/SMV lo que parece importar es, sobre todo, la situación pública conflictiva en la que las emisiones tienen lugar; se trata de actos eminentemente sociales, no de acciones unilaterales o centradas exclusivamente en el emisor.

3) Un énfasis excesivo en la explicitabilidad de los actos ilocucionarios. En el caso de un acto no hostil como prometer, si deseamos no dar pie a equívocos, en lugar de decir: "Vendré mañana" esperando que nuestras palabras se tomen como una promesa, podemos decir: "Prometo que vendré mañana", explicitando entonces cómo pretendemos que sean tomadas nuestras palabras. En contraste, no podemos explicitar que estamos calumniando diciendo "Calumnio...". Si intentamos explicitar que estamos calumniando, nuestro acto se viene automáticamente abajo. Y suena como mínimo extraño decir: "Te amenazo con..." Muchos de los AHH/SMV se explicitan, preferentemente, a través de las atribuciones de los demás ("Fulano calumnió a Mengano"; "Zutano amenazó a Pingano", etc.) y no a través de

\footnotetext{
${ }^{6}$ Eelen (2001) y Watts (2003) señalan que las teorías de la cortesía (anteriores a las suyas) se centran en la conducta cortés y apenas tratan la descortés. Un argumento de Nicoloff (1989) contra el carácter ilocucionario de las amenazas se basa en su carácter no cooperativo, frente al carácter cooperativo, por ejemplo, de las promesas. Este énfasis está inspirado en ideas de Grice (1975). Sin embargo, el Principio Cooperativo (PC) de Grice puede entenderse en un sentido débil, como mera exigencia de hacerse entender y de tratar de entender al otro ( $c f r$. Dascal 2003, p. 339), que abarque también a los AHH/SMV. Así, puesto que las amenazas se realizan a menudo indirectamente, o no explícitamente, el PC podría explicar (al menos en parte) cómo inferimos que determinadas palabras han sido proferidas con el fin de amenazar.
} 
indicadores ilocucionarios introducidos por el hablante en la propia emisión que constituye una calumnia, una amenaza, etcétera.

El estudio de los AHH/SMV puede favorecer el abandono de esos prejuicios (o su matización), lo cual es necesario, a nuestro entender, para avanzar en la construcción de una teoría de los actos de habla con adecuados fundamentos filosóficos. Es cierto que no debemos exagerar la importancia de los AHH/SMV. Nuestras conversaciones son, en general, esfuerzos cooperativos, y transcurren casi siempre en un tono amigable y cortés. Pero hay clases de conversación, como las disputas, controversias, discusiones, etc., en las que encontramos una gran cantidad y variedad de AHH/SMV. ${ }^{7}$ Nuestros cálculos (a ojo; sería interesante realizar una investigación empírica seria al respecto) señalan que los $\mathrm{AHH} / \mathrm{SMV}$ suponen, tanto cuantitativa como cualitativamente, del 10 al 20 por ciento del total de nuestros actos de habla, ${ }^{8}$ lo suficiente como para que no se puedan considerar meras excepciones con escaso interés teórico.

A continuación plantearemos cuatro problemas a los que nos enfrentamos cuando tratamos de integrar los AHH/SMV en un estudio general de los actos de habla: 1) ¿Son actos ilocucionarios o perlocucionarios? 2) ¿Son actos autónomos, o formas de ser desafortunados otros actos? 3) ¿Pueden ser tratados desde la perspectiva del emisor, o invitan a adoptar una perspectiva de tercera persona, centrada en el espectador? 4) ¿Pueden ser integrados en una teoría general de los actos de habla? Pero antes, una última aclaración. No queremos afirmar que problemas como ésos se planteen sólo en el estudio de los AHH/SMV. La hipótesis que guía esta investigación es que un estudio detallado de los AHH/SMV nos permite replantear de un modo preciso algunas importantes cuestiones fundacionales de la teoría de los actos de habla, porque, en este dominio, ciertos rasgos generales de los actos de habla se presentan aumentados y piden de un modo urgente ser explicados, sin que sea posible obviarlos o minimizar su importancia. El estudio de los AHH/SMV se presenta

\footnotetext{
${ }^{7}$ En Johnson y Lakoff (1980) se estudia una metáfora que, según los autores, estructura nuestra manera de conceptualizar las discusiones: UNA DISCUSIÓN ES UNA GUERRA. La idea es que cuando discutimos, o cuando describimos una discusión, utilizamos un lenguaje bélico: "Tus afirmaciones son indefendibles", "Atacó todos los puntos débiles de mi argumento", "Sus críticas dieron justo en el blanco", "Destruí su argumento", "Nunca le he vencido en una discusión", etc. Si conceptualizamos así nuestras discusiones, no es raro que estén repletas de actos ilocucionarios hostiles.

${ }^{8}$ El aspecto cualitativo es más fácil de decidir. En una clasificación amplia, como la de Wierzbicka (1987), el número de verbos de AHH/SMV representa más del 15 por ciento sobre el total de los estudiados.
} 
como una terapia contra los prejuicios teóricos que han deformado nuestra visión de los actos de habla.

\section{3. ¿llocucionarios o perlocucionarios?}

¿Apuntan los verbos de la lista (o la mayoría de ellos) a actos de habla ilocucionarios, equiparables a actos ilocucionarios paradigmáticos como pedir, prometer o saludar, o apuntan más bien a actos de habla perlocucionarios, equiparables a convencer, ofender o disuadir? Una de las tácticas de quienes consideran que los AHH/SMV son secundarios o marginales es expulsarlos del reino de lo ilocucionario, el corazón de la teoría de los actos de habla, hacia la región, en principio menos interesante, de lo perlocucionario. Esto es lo que hacen Nicoloff (1989) o Habermas (1991) con las amenazas. Si la mayoría de los AHH/SMV fuesen actos perlocucionarios, su estudio no ofrecería ninguna luz especial sobre la noción central de la teoría de los actos de habla: la noción de fuerza (aunque tal vez ello aumentaría el interés teórico del estudio de los actos perlocucionarios). La situación parece ser la siguiente. La mayor parte de los teóricos de los actos de habla (incluido John Searle) consideran que los AHH/SMV son actos ilocucionarios, aunque marginales, periféricos, no paradigmáticos, etc. Pero algunos autores van más lejos, afirmando no que esos actos de habla sean secundarios, sino que no son actos ilocucionarios en absoluto. La alternativa más común es considerarlos actos perlocucionarios, que realizamos no al decir algo (in saying something), sino por el hecho de decir algo (by saying something), siendo, por tanto, consecuencias o efectos de actos (ilocucionarios) más básicos. ${ }^{9}$ Esta estrategia es una instancia de una estrategia más amplia, también común, de considerar como perlocucionario todo aquello que no encaje en nuestra teoría favorita acerca de la fuerza. La teoría se autoprotege de ese modo contra cualquier evidencia en su contra: no es que éste o aquel acto ilocucionario no encajen con nuestra teoría, es que, en realidad, no son actos ilocucionarios en absoluto, sino actos perlocucionarios, o alguna otra cosa.

La primera respuesta que se puede dar a esta estrategia es que la hostilidad puede estudiarse en un nivel claramente perlocucionario, y esto ayuda a ver por qué los verbos de nuestra lista apuntan a algo diferente. Así, se pueden considerar como actos perlocucionarios ofender, entristecer, enojar, asustar (atemorizar, aterrorizar), intimidar, deprimir, humillar, desanimar, descorazonar, desilusionar,

\footnotetext{
${ }^{9}$ Otra alternativa sería considerarlos actos de habla ajenos a la clasificación tripartita austiniana, como hace el propio Austin con actos como bromear.
} 
decepcionar, etc. Aunque estos actos suelen ser considerados como hostiles (y reprobables), y se realizan a menudo con palabras, no aparecen en la lista inicial, y no creemos que deban aparecer. Parece claro que la misma asimetría que encontramos entre argumentar y convencer (el acto ilocucionario, más básico, que causa el acto perlocucionario, dependiente del primero), la encontramos entre insultar y ofender, o entre amenazar y atemorizar (o intimidar). Pero si necesitamos fortalecer las intuiciones acerca del carácter ilocucionario y no perlocucionario de los $\mathrm{AHH} / \mathrm{SMV}$, podemos ponerlas a prueba a través de algunos sencillos experimentos como los siguientes:

a) Para comprobar si un acto de habla es ilocucionario podemos hacernos esta pregunta: ¿Está al mismo nivel que un acto ilocucionario paradigmático? En concreto, ¿se pueden hacer de un modo natural preguntas de las formas: "¿Se trató de un(a) $X$ o de un(a) $Y$ ?", "¿Me estás Xndo o me estás $Y n d o ? "$, donde $X$ es el nombre de un AHH/SMV candidato a contar como ilocucionario e $Y$ es el nombre de un acto ilocucionario paradigmático? Si la respuesta es positiva, es probable que nuestro acto sea ilocucionario. El caso más debatido, el de las amenazas, puede ser dirimido de ese modo. Podemos poner las amenazas al mismo nivel que actos ilocucionarios paradigmáticos en preguntas como: “¿Me estás amenazando, o me estás aconsejando?” (Imaginemos que el interlocutor ha dicho: "Yo que tú saldría de la ciudad.") En preguntas como ésa se pone de manifiesto que estamos ante especies de un género común, y no ante cosas completamente dispares. En cambio, no parece legítimo tratar de combinar en una pregunta parecida un acto ilocucionario típico con un acto perlocucionario típico: “¿Lo estás prometiendo o me estás alegrando?”; "¿Lo estás afirmando o me estás convenciendo?" En esos casos se intenta poner al mismo nivel (como alternativas posibles) cosas que no lo están en absoluto.

b) Posibilidad de denegación explícita. Los actos perlocucionarios dependen, para su éxito, sobre todo, de ciertos efectos causados sobre la audiencia, o sobre el mundo. Por eso, no están bajo el control inmediato del hablante: es el mundo, con su encadenamiento de causas y efectos, el que desempeña el papel decisivo. Por eso, cuando se produce el efecto, el hablante no puede hacer nada por evitarlo (aunque a menudo habrá tratado de producirlo). Si la audiencia se ofende o se asusta a través de mis palabras, no puedo evitarlo diciendo: No te estoy ofendiendo, o No te estoy asustando. Ahora bien, aunque es bastante habitual considerar que no podemos amenazar explícitamen- 
te, ${ }^{10}$ sí es habitual realizar la correspondiente denegación explícita: No te estoy amenazando, sólo te estoy advirtiendo. Esa denegación, si es afortunada, puede hacer que mis palabras originales no se tomen como una amenaza. Pero si con mis palabras he ofendido a alguien, no puedo anular o cancelar mi acto diciendo: No te he ofendido.

c) Podemos preguntar, en el caso de los actos ilocucionarios típicos: "¿Lo estás haciendo?"; en cambio eso no resulta natural cuando el acto es perlocucionario (en la mayoría de los casos, lo natural es preguntar al oyente, ya que la realización de un acto perlocucionario típico depende de la producción de efectos en la audiencia). Así, resulta tan natural preguntar: "¿Es una amenaza?" como "¿Es una promesa?"; pero no resulta natural preguntar: "¿Es una ofensa?", o "¿Es una intimidación?”, ya que el oyente debería saberlo mejor que el hablante.

Esos experimentos no son definitivos, y reposan excesivamente en nuestras intuiciones como usuarios competentes del lenguaje, pero son indicadores fiables de que amenazar debe estar al lado de pedir y de prometer, y no al lado de ofender y de convencer. ¿Por qué, entonces, se ha considerado que las amenazas (y otros AHH/SMV) son actos perlocucionarios? En la literatura se manejan tres argumentos. En general, esos argumentos se plantean en relación con casos concretos y muy escasos. El único $\mathrm{AHH} / \mathrm{SMV}$ que ha recibido atención detallada es el de amenazar. ${ }^{11}$

1) Argumento convencionalista. Nicoloff (1989) argumenta que si las amenazas fuesen actos ilocucionarios, entonces plantearían un reto a un punto de vista convencionalista acerca de la fuerza como el que él mismo defiende (frente a las teorías "intencionalistas", que él rechaza). Así que considera necesario demostrar que no son actos ilocucionarios. El convencionalismo defendido por Nicoloff está

${ }^{10}$ En realidad, existen mecanismos explicitadores para las amenazas, como el consabido "tono" amenazante ( $c f r$. Austin 1962, p. 74). De hecho, se puede utilizar el verbo amenazar "casi" realizativamente. En la película Caché, de Michael Haneke, un personaje pregunta: “¿Me estás amenazando?”, y el interpelado responde: "Sí, te estoy amenazando." Muchos teóricos de los actos de habla, como Nicoloff, asumen que tal cosa no se puede hacer, pero no creemos que haya nada especialmente extraño en ese diálogo. Simplemente, en situaciones de conflicto abierto no nos importa aparecer como si estuviéramos haciendo algo malvado con nuestras palabras, e incluso puede convenirnos.

${ }^{11}$ Nicoloff 1989, Habermas 1991, Walton 2000. Los filósofos del derecho han empezado a explorar el campo de los delitos que se cometen con palabras aplicando herramientas de la teoría de los actos de habla (cfr. Alcácer Guirao 2004, Polaino Navarrete y Polaino-Orts 2004, Ruiz Antón 1999). 
inspirado en el de Austin. Los actos ilocucionarios serían convencionales al menos en el sentido de que es posible encontrar un vehículo (verbal) que sirva para realizarlos de forma explícita. El problema es que no parece haber mecanismos convencionales para amenazar; no suena natural decir: "Te amenazo. .." como suena natural decir: "Te prometo. .." 12 Esto se aplica incluso con mayor claridad a actos como calumniar, criminalizar, descalificar o prevaricar. El problema se plantea ya en Austin (1962), al hilo de la cuestión de la explicitación mediante la "forma normal" del realizativo. Así, mientras que puedo prometer explícitamente diciendo "Prometo", no parece que pueda insultar o reprender explícitamente diciendo "Te insulto" o "Te reprendo" (Austin 1962, p. 68). La forma normal para realizar actos ilocucionarios consiste en utilizar un verbo realizativo (o ilocucionario) en la primera persona singular del presente de indicativo y voz activa. Las amenazas, los insultos y otros actos de habla hostiles no se dejan someter fácilmente a este esquema y son, por ello, para un convencionalista como Nicoloff, problemáticos.

Contra este argumento se puede decir, en primer lugar, que está demasiado sesgado por el intento de preservar el marco teórico convencionalista. En segundo lugar, muchos de los actos ilocucionarios de la lista son explicitables, aunque a menudo no sean explícitos de hecho. El caso más claro en el que son explícitos es cuando están legitimados institucionalmente (condenas, degradaciones, multas, etc.). En tercer lugar, tenemos los experimentos que hemos visto, que indican que $\mathrm{AHH} / \mathrm{SMV}$ como las amenazas o los insultos están al mismo nivel que actos ilocucionarios paradigmáticos, y que son explicitables hasta cierto punto, por ejemplo, mediante preguntas que obliguen al interlocutor a pronunciarse diciendo cosas como: "Sí, te estoy amenazando"; además, es posible negarlos explícitamente, y sería raro que fuese ilocucionaria (por convencional en el sentido de Nicoloff) la denegación de un acto perlocucionario, por ejemplo, que "No te estoy amenazando" expresase una denegación ilocucionaria, a pesar de que las amenazas fuesen actos perlocucionarios. En cuarto lugar, existen motivos evidentes de por qué los hablantes no suelen ser explícitos a la hora de realizar AHH/SMV. Estos actos suelen estar socialmente mal vistos, con lo cual realizarlos explícitamente es como reconocer que uno está haciendo algo reprobable. Algunos de esos actos de habla incluso son ilegales, realizarlos con éxito es

12 Las amenazas se suelen "disfrazar" de advertencias, consejos, promesas, etc.: "Te advierto que te apartes de mi mujer", "Te aconsejo que te andes con cuidado", "Te prometo que me las pagarás". 
cometer delitos con palabras; ésa es una buena razón para que un hablante prudente no sea explícito. De ese modo, puede tratar de "nadar y guardar la ropa", por si las cosas se ponen feas. Así, si dijo: "Yo que tú abandonaría la ciudad", podrá alegar luego: "No lo amenacé, sólo le di un consejo." Por último, en quinto lugar, existe un considerable número de miembros de la lista que son no explicitables en un sentido fuerte: son esencialmente no explícitos, no se podrían inventar medios convencionales para que el hablante dejase claro que los está realizando. Se trata de verbos que indican actos algunas de cuyas condiciones constitutivas deben permanecer ocultas o ser de algún modo inconfesables. El calumniador, por ejemplo, debe presentarse como alguien que da una información verdadera. Sin embargo, puesto que están en continuidad con los demás, no se ve por qué deben ser excluidos. Si el convencionalista alega que la razón es que no son convencionalizables asume, más que probar, que estos actos son perlocucionarios.

2) Argumento intencionalista. Para intencionalistas griceanos como Strawson (1964), algunos actos de la lista, como jactarse, no son ilocucionarios, sino perlocucionarios, porque en ellos no se ejemplifica el procedimiento griceano, según el cual el hablante intenta producir un efecto en la audiencia mediante el reconocimiento mismo de ese intento. Cuando, por ejemplo, advierto a $A$ de que $p$, intento que $A$ se ponga en alerta sobre los peligros que acarrea $p$ porque reconozca que yo intento que se ponga en alerta. Pero, en cambio, cuando me jacto, intento que mi audiencia me admire, pero no gracias a que reconozca mi intento de que la admire, sino porque reconozca por sí misma mis méritos. Muchos otros miembros de la lista son no griceanos del mismo modo.

Contra este argumento, podemos alegar que muchísimos actos ilocucionarios no hostiles tienen una fuerza que no puede estar inducida meramente por el procedimiento griceano. Así, cuando argumento o informo, no intento que mi audiencia crea algo sólo porque reconoce mi intención de que lo crea, sino más bien porque reconozca la fuerza de mis argumentos, o porque crea que soy fiable acerca del asunto en cuestión (como un termómetro es fiable acerca de la temperatura). El problema no está en los AHH/SMV, sino en la restrictividad de algunos modelos intencionalistas.

3) Argumento ético-discursivista. Tal vez el defensor más conocido del punto de vista de que los actos de habla hostiles son perlocucionarios es Jürgen Habermas. Puesto que él quiere ligar la noción 
de fuerza ilocucionaria a la búsqueda cooperativa de consenso, a la "racionalidad comunicativa" (en cuanto diferente de la meramente "estratégica"), pretende desplazar los supuestos actos ilocucionarios hostiles (por ejemplo, las amenazas) al ámbito de lo perlocucionario, el cual se caracteriza por un tipo de racionalidad meramente instrumental o estratégica (medios-fines).

Teniendo en cuenta las numerosas analogías existentes entre los AHH/SMV y los actos ilocucionarios paradigmáticos, sólo quien esté sesgado de antemano por un modelo ético de la comunicación puede aceptar el criterio habermasiano para separar lo ilocucionario de lo perlocucionario. Modelos como el de Habermas, más que argumentar que los AHH/SMV son perlocucionarios, lo asumen. ${ }^{13}$

En la teoría "ortodoxa" de los actos de habla los AHH/SMV se admiten sin demasiados escrúpulos entre los ilocucionarios, ${ }^{14}$ aunque no se les concede especial atención. De hecho, la mayoría de ellos aparece en las taxonomías habituales. ${ }^{15} \mathrm{El}$ problema no está en los $\mathrm{AHH} / \mathrm{SMV}$, sino en ciertos modelos teóricos reduccionistas que pretenden analizar la fuerza ilocucionaria en términos de algún factor como el significado convencional de ciertas expresiones y construcciones gramaticales, las intenciones individuales del emisor, o cierta forma de racionalidad. Puesto que la realidad no se deja atrapar en esas redes simplificadoras, se decide arrojar todo aquello que no encaja en el modelo preferido al "cubo de la basura" de lo perlocucionario. Pero la estrategia de desplazar los $\mathrm{AHH} / \mathrm{SMV}$ a la región de lo perlocucionario fracasa, lo cual no excluye que se nos haya colado algún verbo perlocucionario en la lista inicial.

Un buen modo de argumentar a favor de la consideración de los AHH/SMV como ilocuciones consiste en apelar a modelos teóricos explicativos en pragmática que los hagan aparecer como tales. Por ejemplo, podemos ver qué nos dicen sobre la hostilidad verbal algunas teorías acerca del fenómeno de la cortesía. Muchos AHH/SMV

\footnotetext{
${ }^{13}$ Cfr. Habermas 1991. En obras más recientes, Habermas parece haber matizado su punto de vista.

${ }^{14}$ Cfr. la respuesta de Searle a Habermas, en Searle 1991.

${ }^{15}$ Incluidos los más problemáticos. Así, Daniel Vanderveken clasifica calumniar como representativo, y lo define así: "Calumniar es acusar falsamente con la intención perlocucionaria de confundir (mislead) y 'acusar infundadamente' (misacuse)" (Vanderveken 1990, p. 179; la traducción es mía). Así, considera que la falsedad y la insinceridad son condiciones constitutivas de una calumnia. Pero, dado que ésas son formas paradigmáticas de "infortunio" verbal, ¿no estamos desdibujando la distinción entre actos ilocucionarios exitosos y actos ilocucionarios desafortunados? Véase, al respecto, la próxima sección.
} 
están en el extremo de la descortesía, ya que son intrínsecamente descorteses. Otros ponen en riesgo las relaciones sociales, y resultan descorteses a menos que se haga algo por evitarlo. Nos ceñiremos al modelo de la cortesía de Leech, uno de los más conocidos. Leech (1983) ofrece una taxonomía de los actos ilocucionarios basada en la función ilocucionaria, ${ }^{16}$ de acuerdo con la forma en la que se relacionan con "el objetivo social de establecer y mantener el buen entendimiento":

1. Convivencial: Acciones que apoyan la cortesía (agradecer, felicitar, saludar, ofrecer, invitar... ).

2. Colaboradora: Acciones prácticamente indiferentes a la cortesía (afirmar, informar, anunciar...).

3. Competitiva: Acciones que entran en conflicto con la cortesía (preguntar, pedir, ordenar...).

4. Conflictiva: Acciones dirigidas frontalmente contra el mantenimiento de la relación entre los interlocutores (amenazar, acusar, maldecir... ).

Leech centra su atención en las ilocuciones convivenciales y competitivas, ya que en ellas entran en juego de modo especial las máximas de cortesía que propone. Las colaboradoras son neutrales al respecto, mientras que las conflictivas (las que venimos denominando "hostiles") se oponen a la cortesía. Así, en cierto modo, también en este modelo los actos ilocucionarios hostiles se dejan de lado, al ser considerados menos interesantes que otros. Pero al menos se les concede un lugar natural en una taxonomía funcional previa de los actos ilocucionarios. Cualquier modelo de la cortesía tiene que admitir actos ilocucionarios hostiles, al lado de los amistosos y de otros que son más o menos neutrales. De hecho, si como hace Leech, construimos escalas de cortesía, los actos ilocucionarios intrínsecamente hostiles ocuparán un lugar de honor (o de deshonor) en uno de los extremos, el descortés.

Parece pues que existen actos ilocucionarios hostiles y/o socialmente mal vistos, que no todos, ni la mayoría, de los AHH/SMV de la lista inicial son perlocucionarios. No debemos, sin embargo,

\footnotetext{
${ }^{16}$ Esta clasificación se establece como alternativa a la más conocida de Searle ( $c f r$.
} Searle 1975). 
apresurarnos, ya que hemos de enfrentarnos todavía a otro problema, relacionado no tanto con que los $\mathrm{AHH} / \mathrm{SMV}$ sean ilocucionarios como con que sean realmente actos.

\section{4. ¿Actos o infortunios?}

La cuestión aquí tiene que ver con un rasgo de algunos de los miembros de la lista: parece que una de las condiciones constitutivas de la realización exitosa de los correspondientes actos verbales (tal vez la principal) reside en su insinceridad, en algún elemento oculto, malicioso o inconfesable. Pero, habitualmente, la insinceridad se trata como un defecto de un acto de habla, no como una de sus posibles condiciones constitutivas. Así, una promesa insincera es una promesa reprochable, no realizada de modo completamente satisfactorio, y no un acto ilocucionario independiente; pero una calumnia (prevaricación, injuria, difamación...) requiere, precisamente para su éxito pleno, un elemento de insinceridad, ocultamiento o falta de transparencia. Una posible segunda estrategia para minimizar el impacto de los AHH/SMA podría consistir en tratarlos no como actos de habla autónomos (ya sea ilocucionarios o perlocucionarios), sino como modos en los que otros actos de habla pueden salir mal o resultar defectuosos. Así, por ejemplo, una exageración podría verse no como un acto de habla por sí mismo, sino como una afirmación aberrante o reprochable.

La noción de infortunio o infelicidad del habla es una de las más importantes que se fraguan en Austin (1962). El tema central del libro es cómo hacer cosas con palabras, pero el autor insiste en que esas cosas que se hacen con palabras requieren, para ser realizadas, mucho más que simplemente proferir las palabras en cuestión. ${ }^{17}$ A menudo las palabras no son eficaces (o lo son, pero con reparos) debido a que no se dan ciertas condiciones de felicidad. Austin propone un conjunto de tales condiciones, cuyo cumplimiento garantiza la plena e irreprochable realización de un acto verbal. En paralelo, ofrece su teoría de los infortunios, de las diversas cosas que pueden ir mal cuando tratamos de hablar realizativamente. Y ofrece una clasificación bastante elaborada de los infortunios, con dos grandes clases (y varias subclases). Los desaciertos son infortunios de tal gravedad que provocan que el acto ni siquiera se realice (que sea nulo). Así, no puedo divorciarme de alguien diciendo: "Me divorcio de ti", porque

\footnotetext{
${ }^{17} \mathrm{Y}$ también algo más que ligar esas palabras con ciertos estados mentales. Para Austin, lo fundamental es que se den ciertas condiciones externas, ligadas a instituciones extralingüísticas o prácticas sociales.
} 
falta el procedimiento convencional para divorciarse de ese modo, ni puedo apostar cuando la carrera ya ha terminado, o cuando el otro no dice: "Acepto", etc. Las condiciones de felicidad cuyo incumplimiento produce desaciertos son condiciones necesarias para el éxito de un realizativo. En cambio, los abusos son infortunios menos graves, ya que no impiden que el acto se realice, aunque lo vuelven reprochable o no completamente satisfactorio. Así, una promesa insincera es todavía una promesa (aunque reprochable o defectuosa), como también lo es una promesa "inconsecuente", en la que el hablante no hace nada por cumplir con lo prometido. Es importante señalar que contamos con nombres para ciertas clases de infortunios. Así, cuando todo va bien, decir: "Sí quiero" es un modo de casarse. Pero si uno ya está casado, entonces no se casa una segunda vez cuando dice: "Sí quiero." A pesar de eso, tenemos la denominación bigamia, lo cual nos puede confundir, ya que, como dice Austin, "a pesar del nombre, uno no se casa dos veces cuando es bígamo" (Austin 1962, p. 17). "Bigamia" parece, entonces, el nombre de un intento frustrado de hacer algo con palabras, no el nombre de un acto de habla independiente. Por otra parte, estamos ante un desacierto verbal que constituye, además, un delito: cometer el delito de bigamia.

¿Podemos analizar, en general, los AHH/SMV como infortunios (desaciertos o abusos), y no como actos (ya sean ilocucionarios o perlocucionarios) autónomos? La mayoría de los AHH/SMV no pueden ser despachados de ese modo, ni siquiera ampliando la noción de infortunio hasta hacerla irreconocible. ¿Acaso una amenaza debe verse como una advertencia o como una promesa desafortunadas? ¿En qué sentido? Después de todo, yo nunca intenté prometer o advertir, sino precisamente amenazar. Hablamos con toda naturalidad de que una amenaza se realizó de un modo plenamente afortunado, y también podemos enumerar una serie de razones por las cuales una amenaza es desafortunada, por ejemplo, si aquel al que va dirigida no tiene nada que temer del hablante. ${ }^{18}$ Esto es, a los AHH/SMV se les aplica la distinción afortunado/desafortunado. En cambio, hablar de "bigamias" desafortunadas es absurdo.

Existen algunos verbos dentro de la lista que tal vez podrían abandonarla, pasando a engrosar la lista de infortunios. Esto limitaría nuestro proyecto de utilizar las enseñanzas obtenidas en el estudio de los actos ilocucionarios hostiles para replantear el estudio de los

\footnotetext{
${ }^{18}$ El infortunio podría ser clasificado, en la taxonomía de Austin, como un desacierto por Mala Aplicación, similar al caso del que intenta hacer una apuesta cuando la carrera ya ha finalizado.
} 
actos ilocucionarios en general. Nos referimos a aquellos verbos que implican un elemento de insinceridad, o de falsedad, o de ambas, como condición necesaria para que podamos decir que se aplican a una emisión: tergiversar, dar falso testimonio, demagogia, exagerar, infundio, intoxicar, pero también criminalizar, satanizar, demonizar, calumniar, infamar, difamar, injuriar, etc. Es cierto que algunos de ellos son admitidos como actos ilocucionarios dentro de las clasificaciones ortodoxas, pero podría alegarse que esas clasificaciones se fundan en teorías defectuosas.

En nuestra opinión, estamos, en general, ante actos ilocucionarios, y no ante formas de infortunio, pero esto no es fácil de demostrar, en ausencia de un marco teórico sistemático que los incluya o los excluya como tales. En el caso de dar falso testimonio, parece incluso apuntarse al acto ilocucionario con respecto al cual éste es un infortunio: dar testimonio. Y en la definición de "calumnia" de Vanderveken (1990) aparece la palabra "misaccuse", lo cual parece indicar que se trata de una acusación reprochable o defectuosa (aunque, por otra parte, también las acusaciones son AHH/SMV). No obstante, si optamos por la estrategia de considerar que estos supuestos actos son, en realidad, infortunios, ello podría producir problemas en otras regiones del dominio de lo (supuestamente) ilocucionario. Así, por ejemplo, una suposición, una conjetura o una hipótesis están esencialmente constituidas por una falta de evidencia, evidencia que es constitutiva, por ejemplo, de las afirmaciones. Si tengo una fuerte evidencia de lo que digo, mis palabras no podrán ser tomadas como una mera suposición, conjetura o hipótesis. ¿Significa esto que suponer, conjeturar o hipotetizar no son actos ilocucionarios autónomos, sino nombres de ciertas infelicidades que pueden sufrir las afirmaciones? Sería bien extraño. Otras fuerzas tienen como condición constitutiva alguna carencia psicológica en la audiencia. Así, no puedo advertir a quien ya es consciente del peligro, o informar a alguien que ya está enterado del asunto. Si la carencia de algún elemento mental o epistémico en la audiencia puede ser un factor constitutivo de la fuerza, ¿por qué no puede serlo una carencia equivalente en el hablante? (Nótese que en todos estos ejemplos hemos manejado tipos paradigmáticos de actos ilocucionarios no hostiles ni socialmente mal vistos.)

Existe una concepción (ortodoxa) componencial de la fuerza según la cual ésta está compuesta por diversos ingredientes. A una fuerza se le pueden añadir nuevos componentes o restricciones, y así se obtiene una nueva fuerza. Si a una afirmación se le añade la condición de contenido proposicional de ser sobre el futuro se 
obtiene una predicción. Si se le añaden ciertas relaciones discursivas con otras emisiones propias o ajenas tenemos una conclusión, refutación, recapitulación, retractación, objeción, etc. ¿No podemos decir algo similar de los miembros de nuestra lista que podrían parecer infortunios? Por ejemplo, tenemos una acusación, le añadimos que el hablante cree que lo que dice es falso y un deseo de hacer daño, y tenemos una calumnia. El concepto de infortunio (sobre todo, el tipo especial de infortunio que Austin denomina "abuso") está ligado originalmente al de reprochabilidad. Una promesa insincera, o inconsecuente, es reprochable. Los AHH/SMV están a menudo socialmente mal vistos, y eso los hace reprochables. Pero también una acción exitosa puede ser reprochable, por ejemplo, un asesinato. Deberíamos entonces desligar más claramente la noción de infortunio de la de reprochabilidad (social o moral), o corremos el riesgo de que la propia distinción felicidad/infelicidad se nos desdibuje (como otras distinciones austinianas).

Concluimos que la estrategia de tratar los AHH/SMV como infelicidades funciona, si acaso, sólo para un pequeño número de los miembros de la lista inicial. Incluso los casos más problemáticos parecen ofrecer buenas respuestas a la pregunta: ¿Qué fue lo que $H$ hizo?, así que resulta natural tratarlos como actos, no como infortunios. Si sumamos el posible éxito de esta estrategia al que pueda tener la estrategia anterior de desplazar algunos AHH/SMV al ámbito de lo perlocucionario, el territorio inicial de partida podría resultar recortado, aunque no de forma significativa.

\section{5. ¿Primera o tercera persona?}

Tradicionalmente, la teoría de los actos de habla ha privilegiado en sus análisis el punto de vista de la primera persona (el del agente que realiza el acto ilocucionario). Esto se muestra ya en el énfasis austiniano en la "forma normal" para el realizativo, presidida por un verbo en primera persona del singular del presente de indicativo y voz activa ("Prometo", "Lego", etc.), y se ha radicalizado en las teorías postaustinianas de la fuerza, de marcado carácter intencionalista. ${ }^{19}$ La preponderancia analítica de las intenciones del emisor y de su perspectiva de primera persona se puede expresar en forma del siguiente principio metodológico, generalmente aceptado:

(PPPPP) Principio de la Prioridad de la Perspectiva de la Primera Persona: el estudio de los actos ilocucionarios debe

\footnotetext{
${ }^{19}$ Véase, por ejemplo, Searle 1989, p. 101.
} 
privilegiar los estados mentales individuales del emisor (sus intenciones ilocucionarias).

Los AHH/SMV se realizan habitualmente (y, en algunos casos, necesariamente) de un modo primario o no explícito: la fuerza no se muestra en ningún rasgo formal de la emisión introducido por el emisor. No obstante, los espectadores de esos actos (esto es, terceras personas) tienden a realizar atribuciones de fuerza muy explícitas ("Se jactó", "Calumnió", "Amenazó", etc.), debido a que los actos hostiles o reprobables resultan especialmente notorios y son merecedores de comentario (y de crítica). ${ }^{20}$ De ese modo, el estudio de los AHH/SMV favorece un análisis, desde una perspectiva de tercera persona, que destaque los aspectos intersubjetivos de la fuerza (por encima de los elementos subjetivos). Un ejemplo paradigmático, en el caso de los delitos verbales, es el del juez que decide, a partir de la evidencia disponible, si se ha difamado, calumniado, amenazado, etcétera.

El énfasis en la primera persona responde, en general, a una postura intencionalista que tiene su principal raíz en las ideas de Paul Grice. $^{21}$ En Wierbizcka (1987) encontramos una defensa explícita de esta perspectiva (y de su fundamento mentalista), y un rechazo explícito de una perspectiva basada en la tercera persona, en lo que podemos denominar atribuciones ilocucionarias, esto es, el tipo especial de acto de habla mediante el cual afirmamos que otra persona ha realizado un acto de habla. Así: "Los actos de habla exteriorizan los estados mentales del hablante (su 'Quiero', 'Siento', 'Pienso', etc.). Es perverso, a mi entender, analizar el significado de los actos de habla desde una perspectiva de tercera persona" (Wierzbizcka 1987, p. 15; la traducción es mía).

¿Cómo se enfrenta esta postura a las dificultades relacionadas con la no explicitabilidad de muchos AHH/SMV? Wierzbicka pone toda

\footnotetext{
${ }^{20}$ Estas atribuciones pueden entrar en conflicto con las autoatribuciones del emisor, y no siempre prevalecen las autoatribuciones.

${ }^{21}$ Se puede hacer una interpretación de Grice que dé cabida a un mayor interés por los interlocutores y los repertorios lingüísticos que posibilitan la comunicación (debo esta observación a un árbitro de la revista Crítica). A nuestro entender, sin embargo, el marco griceano (incluso cuando le añadimos ciertos elementos "externistas") no responde adecuadamente a los casos en los que uno realiza un acto ilocucionario que no tenía la intención de realizar (además de responder mal a los actos ilocucionarios que uno intenta pero no consigue realizar), posibilidad que un enfoque más externista admitirá sin mayores problemas, y que Austin reconoció de modo expreso: "por ejemplo, yo puedo ordenarle a alguien que haga algo, cuando no intento ordenárselo" (Austin 1962, p. 106; la traducción es mía). Muchos AHH/SMV se realizan a menudo no intencionadamente, aunque de todas formas se considera responsable al emisor (por ejemplo, por no haber medido bien sus palabras).
} 
su confianza en el 'tono' de la emisión (por ejemplo, el tono amenazante, insultante o acusador), pero es dudoso que algo tan vago como el tono pueda servirnos para distinguir toda la variedad de $\mathrm{AHH} / \mathrm{SMV}$ de la lista. El que calumnia, seguramente, se cuidará mucho de utilizar un "tono calumniador". Una de las consecuencias de concentrarse en los AHH/SMV es el cambio de énfasis en la perspectiva teórica, introduciendo una T entre las muchas Ps del PPPPP, en el siguiente principio metodológico:

(PPPTP): Principio de la Prioridad de la Perspectiva de la Tercera Persona: el estudio de los actos ilocucionarios debe privilegiar las atribuciones ilocucionarias de tercera persona que realizan espectadores bien situados.

Se pueden señalar dos puntos a favor del PPPTP. En primer lugar, la abundancia de las atribuciones ilocucionarias de tercera persona. En la vida ordinaria hacemos constantemente este tipo de atribuciones. En comparación, las explicitaciones de primera persona (e incluso las de segunda persona) son relativamente escasas y, estadísticamente al menos, distan de constituir la forma normal de realizar actos de habla. Esto se acentúa en el caso de los AHH/SMV, ya que casi nunca se realizan explícitamente $\mathrm{y}$, sin embargo, por ser muy "salientes", suelen ser objeto de comentarios explícitos por parte de los "espectadores ilocucionarios". De hecho, el emisor casi nunca reconocerá que ha descalificado, calumniado, amenazado, etc. En segundo lugar, sólo un grupo, aunque numeroso, de actos ilocucionarios es susceptible de un tratamiento basado en la disponibilidad de la forma normal (o de cualquier otro dispositivo explicitador), mientras que todos son atribuibles desde la perspectiva de la tercera persona, con lo cual un análisis elaborado desde dicha perspectiva nos permite un tratamiento uniforme y unificado de los diversos tipos de actos ilocucionarios.

Además de las consideraciones anteriores, podemos presentar una variedad de casos que sólo se dejan tratar desde la perspectiva de la tercera persona. A continuación, se presentan dos tipos de casos así: ${ }^{22}$

a) Indeterminación ilocucionaria deliberada. A veces no somos explícitos porque no deseamos serlo, ya que nos conviene la indeterminación. Si decimos: "Yo que tú, saldría de la ciudad", podemos desear que quede en el aire si deseamos aconsejar, advertir o amenazar al oyente, o incluso describir simplemente lo que nosotros haríamos

\footnotetext{
${ }^{22}$ En Blanco Salgueiro 2007 se ofrece una amplia variedad de tipos de casos.
} 
en esa situación. Así, dejando la fuerza poco definida, cedemos a la audiencia parte de la responsabilidad acerca de la determinación de la misma. ${ }^{23}$ En este caso, el hablante introduce una ambigüedad ilocucionaria deliberada mediante la cual se garantiza una salida airosa, en caso de que más adelante surjan problemas (podrá alegar, por ejemplo: "Nunca pretendí amenazarlo, sino sólo advertirlo"). El hablante evitará entonces introducir en su emisión cualquier signo que pueda interpretarse como una exhibición de la fuerza, puesto que precisamente intenta dejarla indeterminada, o que sean los demás los que decidan la cuestión. Estos actos ilocucionarios son, por lo tanto, esencialmente primarios, esto es, no explicitables. Si el hablante desea que sea el oyente el que decida la cuestión (o se lava las manos al respecto) entonces la explicitación de la fuerza será, en todo caso, tarea del oyente (o de algún otro "espectador ilocucionario" que deba decidir la cuestión, por ejemplo un juez).

b) Alusiones imprudentes. A veces hacemos vagas alusiones que "se cargan" con una fuerza no pretendida. Hace algún tiempo, el presidente de la Generalitat catalana, Pascual Maragall, hizo una alusión a las comisiones que sus predecesores habrían cobrado por la adjudicación de obras a determinadas empresas. Maragall se estaba haciendo eco de un rumor muy extendido, y su emisión no exhibía ningún indicador de que estuviera haciendo una acusación. Sin embargo, teniendo en cuenta quién era y en qué contexto dijo lo que dijo, la prensa, la oposición y la opinión pública en general tomaron sus palabras como una grave acusación, a pesar de que él negó cualquier intención acusatoria. En realidad, algunos de los aludidos tomaron las palabras de Maragall como una calumnia, lo cual introduce interesantes complicaciones, ya que mientras que las acusaciones son al menos explicitables por parte del hablante, las calumnias no lo son. Tal vez un juez podría determinar si, en efecto, se trató de una acusación, o de una calumnia, de lo cual se podrían derivar las correspondientes responsabilidades legales. Podemos suponer que Maragall no tenía intenciones ilocucionarias bien definidas, que estamos ante un caso de imprevisión o imprudencia, ante alguien que ha medido mal sus palabras.

6. ¿Teoría o no teoría?

La inclusión de los AHH/SMV en el dominio que debe cubrir una teoría general de los actos de habla multiplica, sin duda, las dificultades a

23 Leech 1983, p. 71. Leech denomina a este fenómeno "negociabilidad" de la fuerza.

Crítica, vol. 40, no. 118 (abril 2008) 
la hora de construir una teoría sistemática (alrededor de la noción de fuerza), y parece dar argumentos a quienes consideran que es mejor optar por una visión menos unificada del territorio, conforme a la idea segundowittgensteiniana de "aire de familia". En otro lugar (Blanco Salgueiro 2007) hemos explorado las dificultades con las que nos encontramos a la hora de elaborar una teoría sistemática de la fuerza. La fuerza de una emisión no parece reducible a un único factor determinante, ya sea al significado convencional de determinadas expresiones o construcciones gramaticales, a las intenciones u otros estados mentales del hablante, o a las condiciones sociales relacionadas con la autoridad, el estatus o el poder. Tales factores no ofrecen, por separado, condiciones suficientes para que una emisión se cargue con una fuerza típica; y, lo que es más grave, existen múltiples casos en los que tales factores no proporcionan ni siquiera condiciones necesarias.

Todo ello apunta a la necesidad de elaborar un modelo ecléctico que tenga en cuenta la gran heterogeneidad de posibles factores constitutivos de la fuerza de una emisión. O, en caso de que tal modelo heterogéneo no permita una teoría sistemática y unificada de la fuerza, tal vez sólo podamos aspirar a algo más débil, un cuadro lo más ordenado posible de una variedad de cosas que hacemos con palabras, y que comparten ciertos rasgos bajo el modelo del "aire de familia".

Lo que podemos añadir tras nuestro análisis de los AHH/SMV es que las esperanzas de un modelo reductivo de la fuerza se desvanecen todavía más. Estos actos ilocucionarios, en todo caso, ponen de relieve la importancia de los factores sociales relacionados con el conflicto y con el mantenimiento del orden social. Así, suponen un desafío para los modelos centrados en algún principio lingüístico interno (de tipo formal-semántico), y para los modelos centrados en la mente del emisor, que son los enfoques con más predicamento en el mercado. Sin embargo, tampoco se puede decir que esos factores sean irrelevantes. De hecho, es importante atender a la mente del emisor, siquiera porque en muchos casos parece que debe existir algún tipo de voluntad de ocultamiento, o intención aviesa y maliciosa para que el acto se realice. Y el significado de ciertas palabras puede ser importante, sobre todo para la realización de aquellos AHH/SMV que están institucionalizados (multas, sentencias, suspensiones, etc.), los cuales pueden ser impugnados o reclamados por "defectos de forma".

\section{Conclusiones}

He intentado mostrar la amplitud del territorio de los AHH/SMV, lo cual exige no dejarlos de lado en un estudio sistemático de las cosas 
que hacemos con palabras. A continuación, he intentado mostrar que nos enfrentamos a actos ilocucionarios (y a las correspondientes fuerzas), y no a actos perlocucionarios. Asimismo, he tratado de demostrar que no pueden ser tratados en general como infortunios, sino que son actos autónomos, con sus propias condiciones constitutivas. El estudio de estos actos sugiere un cambio de perspectiva teórica del énfasis en la primera persona al énfasis en la tercera persona. En cualquier caso, la teoría de los actos de habla necesita profundizar en su propia posibilidad como teoría. Nuestro enfoque acerca de la fuerza debe tener en cuenta que estamos ante un fenómeno muy heterogéneo, en el cual tienen un importante papel constitutivo los factores relacionados con la interacción social. ${ }^{24}$

\section{BIBLIOGRAFÍA}

Alcácer Guirao, R., 2004, “Cómo cometer delitos con el silencio. Notas para un análisis del lenguaje de la responsabilidad", en E.O. de Toledo et al. (comps.), 2004, Estudios penales en recuerdo del profesor Ruiz Antón, Tirant lo Blanch, Barcelona, pp. 21-50.

Austin, J.L., 1962, How to Do Things with Words, 2a. ed., Oxford University Press, Oxford, 1975.

- 1956/1957, "A Plea for Excuses", Proceedings of the Aristotelian Society, vol. 57, pp. 1-30. (Reimpreso en J.L. Austin 1970, Philosophical Papers, Oxford University Press, Oxford.) [Versión en castellano: "Un alegato en pro de las excusas", en J.L. Austin, 1989, Ensayos filosóficos, trad. Alfonso García Suárez, Alianza, Madrid, pp. 169-192.]

Blanco Salgueiro, A., 2007, "Un rompecabezas acerca de la fuerza", en C. Martínez, J.L. Falguera y J.M. Sagüillo (comps.), Current Topics in Logic and Analytic Philosophy, Universidade de Santiago de Compostela, Santiago de Compostela, pp. 53-77.

-, $2004 \mathrm{a}$, "Actos ilocucionarios explícitos", Revista de Filosofía, vol. 29, no. 1, pp. 99-122.

—_ 2004b, Palabras al viento. Ensayo sobre la fuerza ilocucionaria, Trotta, Madrid.

Brown, P. y S.C. Levinson, 1978/1987, Politeness. Some Universals in Language Usage, Cambridge University Press, Cambridge.

Dascal, M., 2003, Interpretation and Understanding, John Benjamins, Amsterdam.

Eelen, G., 2001, A Critique of Politeness Theories, St Jerome, Manchester.

${ }^{24}$ Este trabajo participa en los proyectos HUM2005-03439, financiado por el Ministerio de Educación y Ciencia de España, y HUM2006-0455/FISO, cofinanciado por el MEC de España y FEDER. 
Grice, H.P., 1975 (1989), "Logic and Conversation", Studies in the Way of Words, Harvard University Press, Cambridge, Mass., pp. 22-40.

Habermas, J., 1991, "Is Intentionality More Basic than Linguistic Meaning?", en Lepore y van Gulick 1991, pp. 31-55.

Johnson, M. y G. Lakoff, 1980, Metaphors We Live by, The University of Chicago Press, Chicago.

Lakoff, R., 1973, "The Logic of Politeness; or Minding Your p's and q's", Chicago Linguistic Society, vol. 8, pp. 292-305.

Leech, N.G., 1983, Principles of Pragmatics, Longman, Londres/Nueva York.

Lepore, E. y R. van Gulick (comps.), 1991, John Searle and His Critics, Blackwell, Oxford.

Nicoloff, F., 1989, "Threats and Illocutions", Journal of Pragmatics, vol. 13, no. 4, pp. 501-522.

Polaino Navarrete, M. y M. Polaino-Orts, 2004, Cometer delitos con palabras. Teoría de los actos de habla y funcionalismo jurídico penal, Dykinson, Madrid.

Ruiz Antón, L.F., 1999, “La acción como elemento del delito y la teoría de los actos de habla: cometer delitos con palabras", en J. Cerezo Mir et al. (comps.), El nuevo Código penal: presupuestos y fundamentos. Libro homenaje al Prof. Dr. D. Ángel Torío López, Comares, Granada.

Searle, J.R., 1991, "Response: Meaning, Intentionality and Speech Acts", en Lepore y van Gulick, 1991, pp. 81-102.

_, 1989, "How Performatives Work", en Linguistics and Philosophy, vol. 12; reimpreso en D. Vanderveken y S. Kubo (comps.), 2002, Essays in Speech Act Theory, John Benjamins, Amsterdam/Filadelfia, pp. 85107.

—, 1975 , “A Taxonomy of Illocutionary Acts", en J.R. Searle 1979, Expression and Meaning. Studies in the Theory of Speech Acts, Cambridge University Press, Cambridge.

Strawson, P.F., 1964 (1971), "Intention and Convention in Speech Acts", Logico-Linguistic Papers, Methuen, Londres, pp. 149-169.

Vanderveken, D., 1990, Meaning and Speech Acts, vol. 1: Principles of Language Use, Cambridge University Press, Cambridge.

Watts, R.J., 2003, Politeness, Cambridge University Press, Cambridge.

Watts, R.J., S. Ide y K. Ehlich (comps.), 1992/2005, Politeness in language. Studies in its History, Theory and Practice, Mouton de Gruyter, Berlín/Nueva York.

Walton, D., 2000, Scare Tactics. Arguments that Appeal to Fear and Threats, Kluwer, Dordrecht.

Wierzbicka, A., 1987, English Speech Act Verbs. A Semantic Dictionary, Academic Press, Londres.

Recibido el 23 de mayo de 2007; revisado el 11 de marzo de 2008; aceptado el 22 de marzo de 2008. 